\title{
Identidade territorial e juventude: a percepção dos jovens do Vale do Rio Pardo/RS sobre o território, por meio da fotografia
}

\author{
Elisângela Rudiger Johan ${ }^{1}$ \\ Ângela Cristina Trevisan Felippi ${ }^{2}$
}

\begin{abstract}
Resumo
Este estudo teve como objetivo compreender como os jovens da região correspondente ao COREDE Vale do Rio Pardo, RS-Brasil, percebem o espaço em que vivem e constroem a identidade do território. $O$ estudo traz a discussão teórica sobre cultura, identidade, juventude e território. $O$ recorte de pesquisa teve como foco jovens de 15 a 18 anos, estudantes do ensino médio de uma escola urbana e privada e de outra, do campo e comunitária. A pesquisa foi qualitativa, envolveu onze jovens, com realização de entrevistas e produção de fotografias. Os resultados sugerem que os jovens vêm de formações sociais distintas e manifestam identidades plurais, percebendo seu espaço a partir dessas formações e de suas vivências cotidianas.
\end{abstract}

Palavras Chaves: Território. Identidade. Jovens. Fotografia.

\begin{abstract}
This study aimed to understand how young people from the region corresponding to COREDE Vale do Rio Pardo, RS-Brasil, perceive the space in which they live and build the territory's identity. The study brings the theoretical discussion about culture, identity, youth and territory. The research focus was on young people aged 15 to 18, high school students from one urban and private school, and from another, from the countryside and from the community. The research was qualitative, involving eleven young people, with interviews and photo production. The results suggest that young people come from distinct social formations and manifest plural identities, perceiving their space from these formations and their daily experiences.
\end{abstract}

Keywords: Territory. Identity. Young. Photography.

\section{Introdução}

A relação social entre os diferentes atores que se apropriam do espaço faz parte do processo de construção social, imprimindo identidade ao território. Perceber e compreender a importância da identidade territorial e os elementos culturais que caracterizam as práticas sociais no território como algo que se constrói em determinado tempo e espaço, por meio

\footnotetext{
${ }^{1}$ Mestre em Desenvolvimento Regional. Professora do Departamento de Comunicação Social da Universidade de Santa Cruz do Sul (UNISC). elisangelajohannfotografias@gmail.com

2 Doutora em Comunicação Social. Professora do Programa de Pós-Graduação em Desenvolvimento Regional da Universidade de Santa Cruz do Sul (UNISC).
} 
de suas próprias características, é fundamental nos estudos sobre desenvolvimento que carregam a perspectiva espacial.

A identidade do território refere-se à capacidade de uma identidade ser reconhecida como única por um coletivo ao longo do tempo, através das características que a individualizam. Tratando mais especificamente sobre identidade cultural ou coletiva, para Castells (1999), ela se dá por meio de um conjunto de significados culturais, experiência de um povo ou um conjunto de atributos culturais inter-relacionados sob outras fontes de significados. As diferentes culturas existentes, com as quais os grupos sociais têm contato, influenciam diretamente a vida dos indivíduos, e cada grupo busca evidenciar determinadas características como sendo pertencentes à sua identidade cultural. A identidade não nasce com o indivíduo, é formada e transformada a partir do vivido. É construída socialmente.

A contemporaneidade caracteriza-se por um período de crise de identidade, provocada em muito pelo acesso que as sociedades e os indivíduos têm a distintas culturas e decorrentes possibilidades identitárias advindas da mundialização da cultura, viabilizada pela expansão global do capitalismo e pela revolução nas tecnologias da informação e da comunicação ${ }^{3}$. Mesmo antes da globalização e da revolução tecnológica das comunicações, as ciências sociais já começavam a questionar a concepção de um sujeito centrado, com identidade única e imutável (HALL, 2011). Os estudos culturais, bem como a psicanálise, provocaram a mudança de paradigma sobre a construção dos sujeitos, ao mesmo passo em que a realidade demonstrava a possibilidade dos indivíduos, transformados em sujeitos pelo processo de identificação, aderirem a distintas identidades decorrentes de suas muitas posições sociais. Contribui para esta crise a intensificação da sociedade do consumo, na qual a identidade também se transforma numa mercadoria possível de ser adquirida.

Os grupos juvenis, talvez mais do que outras categoriais sociais, estão sujeitos a essas identidades múltiplas e mutantes, não só porque ainda estão em formação, mas porque, de alguma forma, têm uma aderência às tecnologias de comunicação e informação e, portanto, acesso à cultura mundializada, com destaque para produtos das indústrias culturais.

\footnotetext{
${ }^{3}$ Neste artigo, tecnologias da informação e comunicação (TICs) são entendidas como também de comunicação, incluindo as mídias, uma vez que medeiam as relações comunicacionais entre as pessoas. Refere-se especialmente às tecnologias surgidas com a revolução digital do final do século XX.
} 
Portanto, o artigo apresenta os resultados de uma pesquisa que buscou compreender como os jovens da região correspondente ao Vale do Rio Pardo ${ }^{4}$, no Rio Grande do Sul, Brasil, relacionam-se simbolicamente com seu território, percebendo- Ihe a identidade ${ }^{5}$. Onze jovens de 15 a 18 anos, de duas escolas de ensino médio, uma urbana e privada e outra escola do campo e comunitária foram convidados a produzir fotografias sobre o território, as quais indicassem o que Ihes fica marcado desse espaço. Após, foram entrevistados por meio de um roteiro semiestruturado. O referencial teórico parte dos estudos sobre território e dos estudos culturais.

\section{Identidade juvenil}

A construção da identidade se dá por meio de um conjunto de significados culturais, experiências de um povo ou um conjunto de atributos culturais inter-relacionados sob outras fontes de significados. Essas fontes de significados se originam dos próprios sujeitos, construídas por eles não só de forma coletiva, mas por meio de um processo individual de significados. Portanto, cada indivíduo desenvolve seus significados dentro da cultura, os quais pertencem à forma de pensar de um coletivo inserido numa história (CASTELLS, 1999).

As representações dos indivíduos tendem a ser manifestadas pelas relações pessoais, que ocorrem no convívio em sociedade, em um mesmo espaço, constituindo, dessa maneira, as identidades territoriais. Cada espaço determinado possui os seus diferenciais, formando, assim, seus conjuntos de hábitos, culturas e práticas sociais, que influenciam diretamente a vida do indivíduo, de maneira que cada grupo acaba buscando evidenciar as suas peculiaridades como sendo pertencentes à sua identidade cultural, ou seja, as identidades são constituídas e reconstituídas com aspectos já existentes, ao longo do tempo e do espaço, e se marcam na diferença, num trabalho de fechamento de fronteiras simbólicas, embora sempre frágil, pois as identidades estão em movimento, assim como a cultura, funcionando como pontos de apego temporários (HALL, 2001).

\footnotetext{
${ }^{4}$ Trabalho apresentado no GT 3. Cultura(s) e Desenvolvimento(s) - III SEDRES, Bllumenau (SC), de 14 a 16 de setembro de 2016.

${ }^{5}$ Este artigo teve uma versão preliminar apresentada no III Sedres - Seminário de Desenvolvimento Regional, ocorrido em setembro de 2016, em Blumenau/SC.
} 
A partir do final do século $X X$, as transformações ocorridas pelas mudanças sociais fizeram com que as categorias de cultura de classe, gênero, sexualidade, etnicidade, raça e nacionalidade se fragmentassem. Martin-Barbero (2008) lembra que a sociedade moderna considera as identidades individuais e coletivas como instáveis e fragmentadas em relação à subjetividade, ou seja, oscilam de acordo com o fluxo de referentes e interpretações, sendo consideradas como algo um tanto frágil, sem centro e em mobilidade contínua.

Para os jovens, a relação social é percebida e assumida de uma forma sensível, e, muitas vezes, expressa-se por meio da comunicação corporal, pelo modo de se vestir, de tatuagens, por manter o corpo de acordo com os padrões da sociedade ou oferecer-lhes resistência. As novas gerações estão envolvidas em um espaço imaginário e emocional, mas a casa e a escola tratam e percebem esse jovem pelo princípio de realidade, muitas vezes, expulsando sua sensibilidade. Nesse sentido, muitos jovens se unem, transitando em grupos, tribos, pares, bandos, turmas, guetos e seitas - e até consumindo drogas -, o que lhes dá a sensação de estar fora de si e do seu eu interior.

Dessa forma, grupos juvenis constroem o seu próprio estilo de se comunicar, de ouvir música, de se vestir, criando seus bens culturais e selecionando o ambiente de diversão e de atuação, muitos tentando escapar de padrões estabelecidos pela sociedade e pela indústria da moda. É em função dessas criações que esses grupos se posicionam e se movimentam no mundo, expressando-se por meio do uso de artigos de consumo e outros objetos que, através de imagens, caracterizam as identidades sociais. O movimento punk, por exemplo, transformou-se em um fenômeno de massa, inclusive no Brasil, nos anos 1880 e 90, e foi um dos primeiros grupos juvenis a surgir no espaço urbano, agindo e manifestando suas ações de uma forma diferente, rompendo com os padrões arcaicos da sociedade e, assim, incentivando outros grupos juvenis a expressarem suas diferentes identidades no espaço social (ABRAMO,1994).

O grande movimento das culturas juvenis contemporâneas contribui para que as identidades não sejam vistas como únicas, iguais, compactas, seguindo um sistema linear (CANEVACCI, 2005). Para Gumes (2003), as diferentes fases históricas dos grupos juvenis, especialmente a partir da segunda metade do século $X X$, comprovam que os jovens possuem identidades distintas: delinquente juvenil, beatnik, hippie, punk, yuppie, comunistas, hip hop, 
clubber, antiglobalizante, entre outras, em um processo permanente de aproximação, distanciamento ou reconstrução.

Assim, não é possível definir os jovens como um grupo homogêneo, mas, sim, como grupos juvenis que constituem um conjunto heterogêneo, jovens com oportunidades, dificuldades, facilidades e poder distintos nas sociedades. A juventude é uma construção social, é a produção de uma determinada sociedade, que se origina de várias formas, produção na qual se conjugam, entre outros fatores, estereótipos, momentos históricos, múltiplas referências, além de diferentes e diversificadas situações de classe, gênero, etnia, grupo, entre outros (ESTEVES; ABROMOVAY,2009).

$\mathrm{Na}$ contemporaneidade, os novos estudos sobre os jovens não procuram tratar de um grupo etário específico, mas, sim, buscam associar os jovens por seus valores e estilos de vida, resultando em novos significados juvenis, pois o jovem vive em um mundo radicalmente novo, cujas categorias de inteligibilidade ele ajuda a construir. Nesse sentido, os meios de comunicação tornam-se um veículo de extrema importância para a integração cultural (PERALVA, 1997).

Para compreender os grupos juvenis, é preciso entender que os jovens constroem as suas experiências, na maioria das vezes, por meio das redes de relações e por meio de significados da cultural global. Sendo assim, o segredo dos jovens contemporâneos é o entrelaçamento do coletivo e do individual. Esse processo de socialização constitui-se por meio de diversas interações e muitas referências culturais, através das quais as experiências vividas pelos jovens adquirem sentidos, e, a partir desses processos, os jovens se constituem (SOUZA, 2004). O consumo cultural é uma influência marcante na formação da identidade juvenil, caracterizada pela socialização, midiatização e estetização, constituindo as práticas sociais de acordo com a concepção de mundo e de tempo.

A noção de que a percepção e a prática do consumo, no cotidiano, estão hoje marcadas por um regime de organização que se caracteriza pela constituição socializadora, midiatizada e estetizada é parte constituinte das práticas sociais desses jovens, que se percebem como parte integrante de um grande sistema hierarquizado de relações sociais (LARA, 2008, p. 135).

A juventude é um grupo social independente. Portanto, o agir se tornou uma oportunidade de experimentar mudanças, e a juventude experiência as transformações de cada época em seu próprio corpo, sem depender de cunho religioso, filosófico e muito 
menos político (MARTIN-BARBERO, 2008). Em uma era de constantes mudanças, de transformações globais, ideologias fragmentadas e ciclos e trajetórias de vida em movimento, a juventude vem sendo capaz de negociar suas próprias vidas em uma realidade global/local.

\section{Identidade territorial}

Da forma semelhante à identidade, o território também é uma construção social, através do resultado de uma ação social que se apropria de determinado espaço. O território está em constante mudança por meio das ações daqueles que fazem parte do seu processo de construção social, criando uma identidade no espaço determinado (RAFESTIN, 1993).

O território pode ser entendido como um espaço vivido, carregado de significados sentimentais e materiais, onde o indivíduo (re)constrói lugares e relações de vivências, atribuindo significado e sentido a esse lugar. E pensar num território é pensar em identidade, um espaço em que os indivíduos sociais produzem seus símbolos e seus significados e expressam a diversidade das relações sociais por meio da identidade.

\footnotetext{
O território é o chão e mais a população, isto é, uma identidade, o fato e o sentimento de pertencer àquilo que nos pertence. $O$ território é a base do trabalho, da residência, das trocas materiais e espirituais e da vida, sobre os quais ele influi. Quando se fala em território, deve-se, pois, de logo, entender que se está falando em território usado, utilizado por uma dada população (SANTOS, 2002, p. 96).
}

O conceito de identidade territorial vem ganhando espaço nos estudos de desenvolvimento, ao mesmo tempo em que se torna um desafio, pois ainda está em construção (HAESBAERT, 1999). "Partimos do pressuposto geral de que toda identidade territorial é uma identidade social definida fundamentalmente através do território" (1999, p. 172). Ainda, complementa o autor, "De forma muito genérica, podemos afirmar que não há território sem algum tipo de identificação e valoração simbólica (positiva ou negativa) do espaço pelos seus habitantes" (1999, p. 172).

Na tentativa de um recorte para o conceito, Perico (2009) sugere que as identidades envolvem um conjunto de características do território que se relacionam com suas origens, com a forma de vivência no espaço, com a construção do conjunto social e a relação 
recíproca entre os indivíduos. E o território seria o espaço em que a diversidade é valorizada, em que os fatores se aglutinam, em que a mediação de interesses é facilitada, fornecendo o entendimento de princípios e convergência.

Dessa forma, identidade territorial está associada ao sentimento de territorialidade, do apego dos indivíduos ao território em que estão instalados e a sua cultura e práticas ativamente deste processo. "[...] territorialidade humana pressupõe também a preocupação com o destino, a construção do futuro, o que, entre os seres vivos, é privilégio do homem" (SANTOS, 2001, p. 19).

\section{A Região em estudo}

O recorte espacial desta pesquisa é a região correspondente ao Vale do Rio Pardo, estipulada pelo recorte do Conselho Regional de Desenvolvimento (COREDE) ${ }^{6}$. A constituição do território correspondente a essa divisão regional se deu com a fundação do município de Rio Pardo, em 1779. A região, antes do tratado de Madrid, era posse espanhola e berço dos índios Tupis Guaranis, passando a ser ocupada e povoada por portugueses, os quais trouxeram os escravos africanos (KARNOPP, 2003).

A ocupação foi intensificada na segunda metade do século XIX, com a formação de colônias de imigrantes europeus de origem germânica. A região como um todo foi aos poucos sendo colonizada pelos agricultores e familiares. Essa base cultural étnica auxiliou na criação do patrimônio cultural, arquitetônico e gastronômico da região, com a presença mais marcante dos germânicos, mas tendo traços também dos portugueses, indígenas, africanos e italianos.

Os primeiros colonos alemães se especializaram na produção do tabaco na região, tornando a produção do fumo uma das principais alternativas econômicas, superando a concorrência com as demais colônias no comércio de produtos na capital (VOGH, 2006). A produção, até o início do século XX, de controle do capital local, foi passando, aos poucos, ao controle do capital transnacional, realidade em que se encontra na atualidade. $O$ Vale do Rio Pardo "[...] é um exemplo de região em que horizontalidades e verticalidades se evidenciam"

\footnotetext{
${ }^{6}$ O Conselho Regional de Desenvolvimento (COREDE) do Vale do Rio Pardo faz parte de uma divisão políticoadministrativa com vistas à participação da sociedade civil na discussão do desenvolvimento, criada pelo governo do Rio Grande do Sul em 1991. O COREDE Vale do Rio Pardo engloba 23 municípios.
} 
(SILVEIRA; CAMPOS, 2012, p. 206). As características Ihe conferem particularidade no âmbito da integração vertical do território brasileiro, com a economia globalizada e, por outro lado, com marcadores e "práticas socioespaciais alinhadas a sua formação territorial" (2012, p. 206).

Em 2015, a população estimada pelo IBGE para a região do COREDE foi de 440.227 habitantes, sendo que os municípios de Santa Cruz do Sul, Candelária, Rio Pardo e Venâncio Aires concentram a maior parte da população, em torno de $60 \%$. Na relação rural-urbano, a concentração maior da população está nas cidades, totalizando 67,30\%, embora o percentual esteja abaixo da média do Rio Grande do Sul, que é de 85,10\% (IBGE, 2010). O principal centro urbano é Santa Cruz do Sul, com uma população de 118.374 habitantes (IBGE, 2010). No entanto, ainda pelo registro de 2010 do Instituto, a região abriga dez municípios, cuja população rural é maior que 70\%.

A população do COREDE do Vale do Rio Pardo está, na sua maioria, situada nas faixas etárias jovem e adulta. Dados da FEE para o Rio Grande do Sul indicam que os jovens de 15 a 19 anos representavam 7,8\% da população gaúcha em 2015, num total de 881.113. No entanto, a população de jovens vem caindo ano a ano, sendo que, em 2001, segundo a FEE, somavam 909.221 pessoas. Tal fato pode ser explicado pela diminuição paulatina da taxa de fecundidade e natalidade, fenômeno nacional que se verifica também na região estudada. Segundo o IBGE, do censo de 2000 para o de 2010, o percentual de população nesta faixa etária baixou de 2,44 para 1,87 na região do COREDE, embora ainda seja superior à média do Rio Grande do Sul, onde esse índice também baixou.

\section{Percurso metodológico}

A pesquisa aqui apresentada buscou conhecer a realidade dos jovens do Vale do Rio Pardo, analisando, por meio das manifestações representativas do seu cotidiano, como percebem a identidade do seu território, a diversidade cultural, e como o processo de construção da identidade territorial ocorre no grupo juvenil. A pesquisa teve caráter qualitativo, sendo realizada uma entrevista com cada um dos jovens selecionados, cujo roteiro foi composto de 32 questões objetivas e dezesseis questões abertas. O objetivo era tanto traçar o perfil sociocultural dos jovens entrevistados, como obter respostas que atendessem aos objetivos mais específicos da pesquisa, com questões sobre o conhecimento 
e sua relação com a região, como percebem o território, como veem e como gostariam que o território fosse visto.

Aos jovens participantes foi solicitado, no primeiro contato com o grupo - para a apresentação da proposta da pesquisa e o convite para participação - e antes da realização das entrevistas, que produzissem com seus aparelhos celulares fotografias que representassem a região, selecionando no máximo dez fotos. As imagens foram utilizadas durante a entrevista, como recurso de mediação das respostas dos jovens, e foram analisadas posteriormente.

A fotografia foi utilizada como uma técnica de pesquisa seguindo a antropologia visual. De acordo com Copque (2003), por meio das fotografias, é possível ter um novo modo de olhar o mundo, tornando enriquecedora a forma de apresentar fatos, objetos, pessoas e acontecimentos. A fotografia tomada como um recurso estratégico na pesquisa possibilita registrar aspectos que, muitas vezes, passam despercebidas pelos olhos, permitindo. Assim, descrever momentos densos, sensíveis e emocionais.

Para a seleção dos jovens participantes da pesquisa, foram definidas duas escolas de ensino médio de Santa Cruz do Sul: uma central, urbana, privada, e outra do campo e comunitária, localizada num bairro próximo à zona rural do município. A escolha da cidade deu-se pela sua posição de polo econômico regional, centralizando diversos serviços, o que resulta na frequente atração de pessoas de outras cidades (FEE, 2010). A opção pelas escolas, por sua vez, foi porque ambas se mostraram um caminho possível de se chegar aos jovens e, para a pesquisa, reunirem características que permitiriam garantir certa diversidade de jovens. A escola urbana, porque nela predominam alunos residentes em áreas urbanas, muitos deles migrados de outras cidades e estados do Brasil e até do estrangeiro. A escolha da escola do campo justificou-se por ter exclusivamente jovens que residem no meio rural de vários municípios da região, e por basear-se na pedagogia da alternância.

Para participar da pesquisa, foram selecionados onze jovens de ambos os sexos, com idade entre os 15 a 18 anos. O critério para participação era possuir um aparelho de celular próprio, com câmera fotográfica, ter interesse em participar da pesquisa e ser residente na região. As entrevistas foram individuais e realizadas nas dependências das escolas. 


\section{Os jovens e a identidade territorial}

Todos os 11 jovens selecionados produziram as fotografias solicitadas e participaram das entrevistas individuais. As entrevistas individuais permitiram, num primeiro momento, organizar um quadro com o perfil dos jovens entrevistados. O perfil indicou que os jovens da escola urbana moram predominantemente no espaço urbano de Santa Cruz do Sul, e os jovens da escola do campo vêm de vários municípios da região do Vale do Rio Pardo e habitam o espaço rural desses municípios. Os jovens dessa escola colocam-se na posição de trabalhadores, uma vez que auxiliam os pais nas atividades agropecuárias. Os jovens urbanos se colocam como estudantes. Embora muitos não soubessem informar a renda familiar, a partir da ocupação dos pais, acredita-se que as famílias se posicionam entre as classes populares e a classe média ${ }^{7}$.

\section{Quadro 1 - Perfil dos jovens participantes da pesquisa ${ }^{8}$}

\begin{tabular}{|c|c|c|c|c|c|c|c|c|c|c|c|}
\hline $\begin{array}{c}\text { Sujeitos } \\
\text { Entrevistados }\end{array}$ & Escolaridade & $\begin{array}{l}\text { Instituição } \\
\text { de Ensino }\end{array}$ & \begin{tabular}{|c|}
$\begin{array}{c}\text { Município } \\
\text { onde } \\
\text { reside }\end{array}$ \\
\end{tabular} & \begin{tabular}{|c|} 
Municípios \\
que já \\
residiu
\end{tabular} & \begin{tabular}{|c|} 
Localização \\
da sua \\
residência
\end{tabular} & \begin{tabular}{|c|} 
Referente \\
à sua \\
ocupação
\end{tabular} & \begin{tabular}{|c|} 
Ocupação do \\
Pai
\end{tabular} & $\begin{array}{l}\text { Ocupação da } \\
\text { Mãe }\end{array}$ & $\begin{array}{c}\text { Escolaridade } \\
\text { do Pai }\end{array}$ & $\begin{array}{c}\text { Escolaridade } \\
\text { da Mãe }\end{array}$ & Renda familiar \\
\hline $\begin{array}{c}\text { Jovem } 01 \text { E.C } \\
\text { (K. } 16 \text { anos/masc.) }\end{array}$ & \begin{tabular}{|c|}
$2^{\circ}$ ano do \\
ensino médio
\end{tabular} & $\begin{array}{l}\text { Escola } \\
\text { comunitária }\end{array}$ & Herveiras & & Zona rural & $\begin{array}{c}\text { Trabalha e } \\
\text { estuda }\end{array}$ & $\begin{array}{c}\text { Operador de } \\
\text { máquinas na } \\
\text { prefeitura de } \\
\text { Herveiras }\end{array}$ & $\begin{array}{c}\text { Merendeira da } \\
\text { Escola São Luis- } \\
\text { Herveiras }\end{array}$ & $8^{\mathrm{a}}$ série & $4^{a}$ série & $2.700,00$ \\
\hline $\begin{array}{c}\text { Jovem } 02 \text { E.C. } \\
\text { (L. } 16 \text { anos/Masc.) }\end{array}$ & \begin{tabular}{|c|}
$1^{\circ}$ ano do \\
ensino médio
\end{tabular} & $\begin{array}{c}\text { Escola } \\
\text { comunitária }\end{array}$ & $\begin{array}{l}\text { Passo do } \\
\text { Sobrado }\end{array}$ & & Zona rural & $\begin{array}{c}\text { Trabalha e } \\
\text { estuda }\end{array}$ & Agricultor & Agricultora & $4^{a}$ série & $4^{3}$ série & $\begin{array}{l}\text { Não sabe } \\
\text { informar }\end{array}$ \\
\hline $\begin{array}{c}\text { Jovem } 03 \text { E.C. } \\
\text { ( L.16 anos/Masc.) }\end{array}$ & $\begin{array}{c}2^{\circ} \text { ano do } \\
\text { ensino médio }\end{array}$ & $\begin{array}{c}\text { Escola } \\
\text { comunitária }\end{array}$ & $\left|\begin{array}{c}\text { Santa Cruz } \\
\text { do Sul }\end{array}\right|$ & & Zona rural & $\begin{array}{c}\text { Trabalha e } \\
\text { estuda }\end{array}$ & $\begin{array}{l}\text { Agricultor e } \\
\text { safrista da } \\
\text { Philip Morris }\end{array}$ & $\begin{array}{l}\text { Empregada } \\
\text { doméstica }\end{array}$ & $\begin{array}{c}\text { Ensino médio } \\
\text { completo }\end{array}$ & $4^{a}$ série & $4.000,00$ \\
\hline $\begin{array}{c}\text { Jovem } 04 \text { E.C. } \\
\text { (M. } 15 \text { anos/Masc.) }\end{array}$ & $\begin{array}{c}1^{\circ} \text { ano do } \\
\text { ensino médio }\end{array}$ & $\begin{array}{c}\text { Escola } \\
\text { comunitária }\end{array}$ & Sinimbu & $\begin{array}{l}\text { Boqueirão } \\
\text { do Leão }\end{array}$ & Zona rural & $\begin{array}{c}\text { Trabalha e } \\
\text { estuda }\end{array}$ & Professor & Professora & $\begin{array}{l}\text { Ensino } \\
\text { superior } \\
\text { completo }\end{array}$ & $\begin{array}{c}\text { Ensino } \\
\text { superior } \\
\text { incompleto }\end{array}$ & $5.500,00$ \\
\hline $\begin{array}{l}\text { Jovem } 05 \text { E.C. } \\
\text { (S.16 anos/ Fem.) }\end{array}$ & $\begin{array}{c}2^{\circ} \text { ano do } \\
\text { ensino médio }\end{array}$ & $\begin{array}{l}\text { Escola } \\
\text { comunitária }\end{array}$ & Vera Cruz & . & Zona rural & $\begin{array}{c}\text { Trabalha e } \\
\text { estuda }\end{array}$ & Agricultor & $\begin{array}{l}\text { Agricultora e } \\
\text { safrista }\end{array}$ & $4^{a}$ série & $\begin{array}{c}\text { Ensino } \\
\text { fundamental } \\
\text { completo }\end{array}$ & $\begin{array}{l}\text { Não sabe } \\
\text { informar }\end{array}$ \\
\hline $\begin{array}{c}\text { Jovem } 06 \text { E.C. } \\
\text { ( V.16anos/Masc.) }\end{array}$ & \begin{tabular}{|c|}
$1^{\circ}$ ano do \\
ensino médio
\end{tabular} & $\begin{array}{c}\text { Escola } \\
\text { comunitária }\end{array}$ & $\begin{array}{c}\text { Passo do } \\
\text { Sobrado }\end{array}$ & Rio Pardo & Zona rural & $\begin{array}{c}\text { Trabalha e } \\
\text { estuda }\end{array}$ & $\begin{array}{l}\text { Agricultor } e \\
\text { ferreiro }\end{array}$ & $\begin{array}{l}\text { Agricultora e } \\
\text { confeiteira }\end{array}$ & $4^{\mathrm{a}}$ série & $8^{\mathrm{a}}$ série & $\begin{array}{c}50.000,00 \\
\text { ano/bruto }\end{array}$ \\
\hline $\begin{array}{c}\text { Jovem } 07 \text { E.P. } \\
\text { (G. } 16 \text { anos/Masc.) }\end{array}$ & $\begin{array}{c}1^{\circ} \text { ano do } \\
\text { ensino médio }\end{array}$ & $\begin{array}{l}\text { Escola } \\
\text { privada }\end{array}$ & $\begin{array}{c}\text { Santa Cruz } \\
\text { do Sul }\end{array}$ & $\begin{array}{l}\text { Curitiba e } \\
\text { Paraná }\end{array}$ & Zona urbana & Estuda & $\begin{array}{l}\text { Trabalha na } \\
\text { Uniar }\end{array}$ & Dona de casa & $\begin{array}{l}\text { Não sabe } \\
\text { informar }\end{array}$ & $5^{a}$ série & $\begin{array}{l}\text { Não sabe } \\
\text { informar }\end{array}$ \\
\hline $\begin{array}{l}\text { Jovem } 08 \text { E.P. } \\
\text { ( J.15 anos/Fem.) }\end{array}$ & $\begin{array}{c}1^{\circ} \text { ano do } \\
\text { ensino médio }\end{array}$ & $\begin{array}{l}\text { Escola } \\
\text { privada }\end{array}$ & $\begin{array}{c}\text { Santa Cruz } \\
\text { do Sul }\end{array}$ & Frasburgo & Zona urbana & Estuda & Administrador & Pedagoga & $\begin{array}{l}\text { Ensino } \\
\text { superior } \\
\text { completo }\end{array}$ & $\begin{array}{l}\text { Ensino } \\
\text { superior } \\
\text { completo }\end{array}$ & $\begin{array}{l}\text { Não sabe } \\
\text { informar }\end{array}$ \\
\hline $\begin{array}{c}\text { Jovem } 09 \text { E.P. } \\
\text { (F. } 17 \text { anos/Masc.) }\end{array}$ & $\begin{array}{c}1^{\circ} \text { ano do } \\
\text { ensino médio }\end{array}$ & $\begin{array}{l}\text { Escola } \\
\text { privada }\end{array}$ & $\begin{array}{c}\text { Santa Cruz } \\
\text { do Sul- } \\
\text { Linha João } \\
\text { Alves }\end{array}$ & & Zona rural & Estuda & $\begin{array}{l}\text { Corretor de } \\
\text { imóveis }\end{array}$ & Contabilista & $\begin{array}{l}\text { Ensino } \\
\text { superior } \\
\text { completo }\end{array}$ & $\begin{array}{l}\text { Ensino } \\
\text { superior } \\
\text { completo }\end{array}$ & $3.200,00$ \\
\hline $\begin{array}{c}\text { Jovem } 10 \text { E.P. } \\
\text { (N. } 15 \text { anos/Masc.) }\end{array}$ & \begin{tabular}{|c|}
$1^{\circ}$ ano do \\
ensino médio
\end{tabular} & $\begin{array}{l}\text { Escola } \\
\text { privada }\end{array}$ & $\begin{array}{c}\text { Santa Cruz } \\
\text { do Sul }\end{array}$ & & Zona urbana & Estuda & Contador & Podóloga & $\begin{array}{l}\text { Ensino } \\
\text { superior } \\
\text { completo }\end{array}$ & $\begin{array}{l}\text { Ensino } \\
\text { superior } \\
\text { completo }\end{array}$ & $\begin{array}{l}\text { Não sabe } \\
\text { informar }\end{array}$ \\
\hline $\begin{array}{c}\text { Jovem } 11 \text { E.P. } \\
\text { (T.15 anos/Masc.) }\end{array}$ & $\begin{array}{c}1^{\circ} \text { ano do } \\
\text { ensino médio }\end{array}$ & $\begin{array}{l}\text { Escola } \\
\text { privada }\end{array}$ & $\begin{array}{c}\text { Santa Cruz } \\
\text { do Sul }\end{array}$ & & Zona urbana & Estuda & $\mid \begin{array}{c}\text { Fiscal da } \\
\text { Receita Federal }\end{array}$ & Aposentada & $\begin{array}{l}\text { Ensino } \\
\text { superior } \\
\text { completo }\end{array}$ & $\begin{array}{l}\text { Ensino } \\
\text { superior } \\
\text { completo }\end{array}$ & $\begin{array}{l}\text { Não sabe } \\
\text { informar }\end{array}$ \\
\hline
\end{tabular}

Fonte: Elaborado pelas autoras.

\footnotetext{
${ }^{7}$ Sem recorrer à maior discussão a respeito, entende-se como classe média a composta pelas camadas sociais com poder de consumo razoáveis, sem privações básicas e com certa possibilidade de realizar atividades de lazer, educação, saúde e acesso à cultura.

${ }^{8}$ Os jovens serão identificados pela primeira letra do nome e por um número numa sequência. As iniciais E.C. significam escola comunitária, e as iniciais E.P., escola privada.
}

COLÓQUIO - Revista do Desenvolvimento Regional - Faccat - Taquara/RS - v. 15, n. 1, jan./jun. 2018 
Uma segunda parte da entrevista se deteve em compreender a relação dos jovens com o território, explorando suas percepções com uso das fotografias. Chegou-se a duas principais constatações: a) há semelhanças entre os jovens quanto a sentimentos e inquietações próprias da condição juvenil; e b) há uma forte vinculação dos jovens com o território vivido, percebida, inclusive, nas diferenças de representações dos jovens de uma escola e de outra com relação ao espaço.

A fala e as imagens dos jovens indicaram a remissão ao cotidiano, ao vivido e experienciado no seu entorno. Imagens e narrativas sobre família, amigos, animais de estimação, escola, lazer, viagens, espaços públicos da cidade (jovens urbanos) e espaço rural da propriedade dos pais e das atividades agrícolas como a produção do tabaco e criação de animais (jovens rurais) são as que predominam na quase totalidade das fotografias trazidas pelos jovens. E a fotografia tem para os jovens o intuito de registrar momentos e emoções que possam ser revividos no futuro, como indicam depoimento e imagem na sequência:

Penso que a nossa imaginação funciona mais, podendo ver alguma coisa do que só ouvir e falar. Além de fotografar, eu costumo imprimir as fotos e guardar em um álbum, porque penso que não podemos ficar totalmente dependentes da tecnologia (...) (Jovem04/E.C./M./16anos/Masc.)

\section{Fotografia 01 - Família}

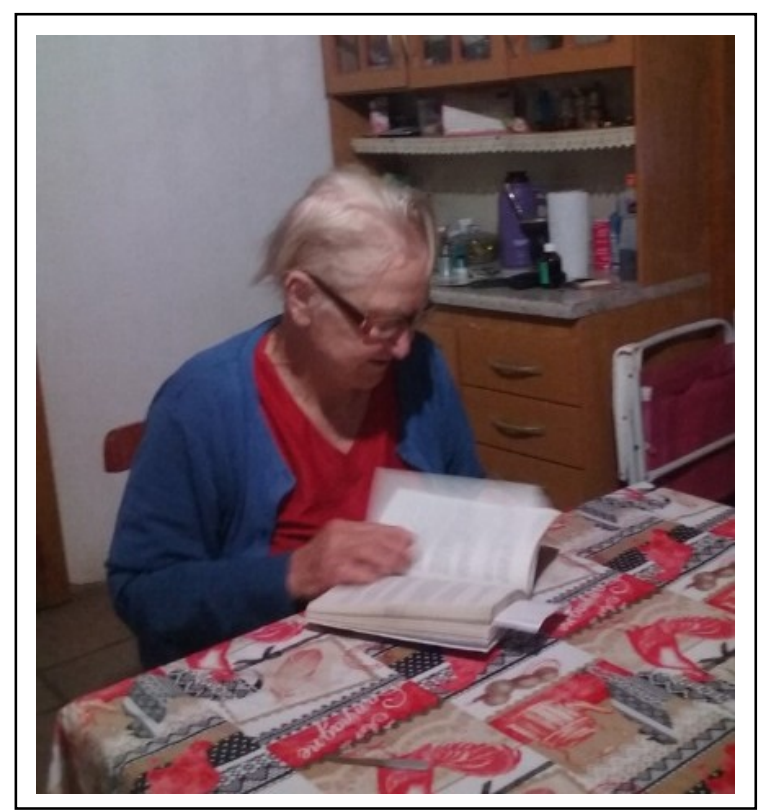

Fonte: Jovem05 E.C./S./16 anos/Fem. 
Mesmo os jovens de ambas as escolas tendo relação semelhante com a fotografia e muito próxima com o território, percebeu-se, talvez até por conta disso, que retratam o território fazendo escolhas distintas e falando de um cotidiano bem diferenciado. Os jovens da escola urbana elegem os espaços públicos da cidade e os espaços de lazer e esporte da escola como os que marcam seu território. Já os jovens da escola do campo se referem também à escola, mostrando fotos de experimentos e visitas técnicas, e à propriedade rural da família, retratando lavouras e criações, e destacando sua rotina ligada à terra e às atividades produtivas nela desenvolvidas.

Geralmente eu fotografo quando eu vejo uma paisagem bonita, aí eu posto no snapchat ${ }^{9}$, mandamos uma foto qualquer só para conversar com amigos, essas não têm muito um porquê. Ou, muitas vezes, fotografo só para postar nas redes sociais (Jovem 11 E.P./F./15 anos/Masc.).

É a imagem do colégio, porque passo um bom tempo da minha vida nele (Jovem 10 E.P/N./15 anos/Masc).

Eu geralmente costumo fotografar a minha égua e os meus cachorros, e o meu maior objetivo é fotografar os meus experimentos na agricultura, em especial as hortaliças (Jovem 01 E.C./K./16 anos/Masc.)

Eu escolhi essas fotografias porque são coisas que eu mais gosto de fazer. Eu não sou muito de ir na casa dos amigos nos finais de semana, eu gosto mais de ficar em casa, mexendo com os meus bichos e trabalhando na minha horta, e gosto de jogar futebol. (...) (Jovem 03 E.C/ L./16 anos/Masc.).

\section{Fotografia 02 - Praça Getúlio Vargas}

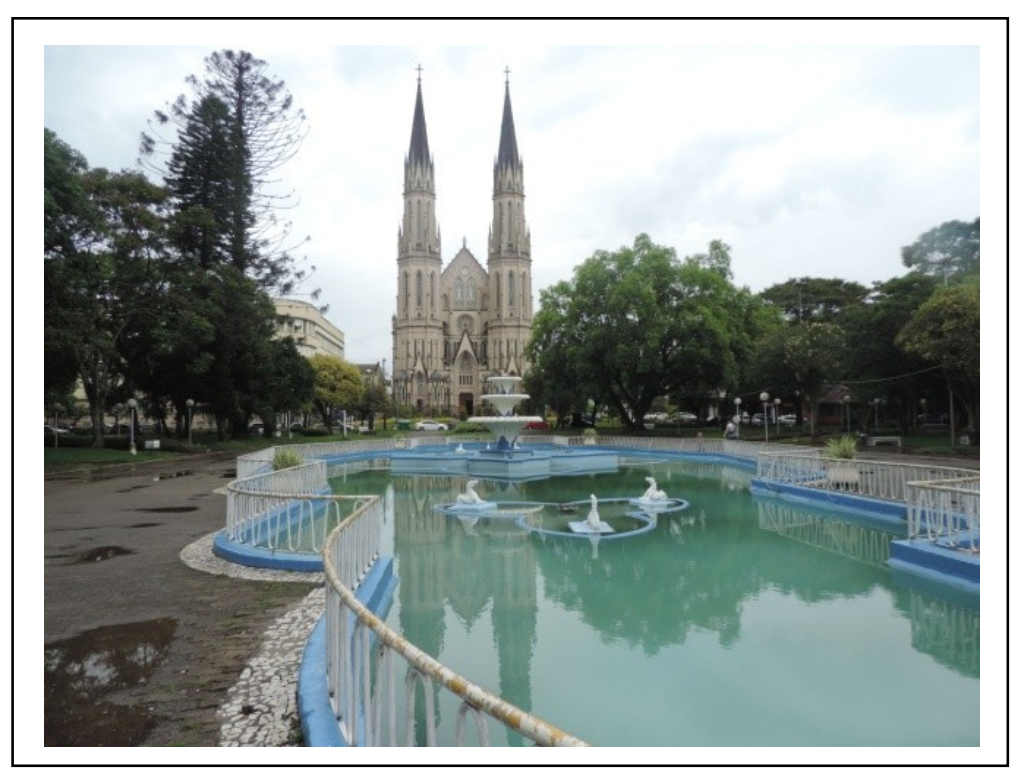

Fonte: Jovem 09 E.P./F.17 anos /Masc.

\footnotetext{
${ }^{9}$ O Snapchat é um aplicativo de troca de mensagens, fotos e vídeos, sendo o foco a troca dos famosos Snaps, que são as fotos ou vídeos instantâneos gravados através do próprio aparelho.
} 


\section{Fotografia 03 - Égua}

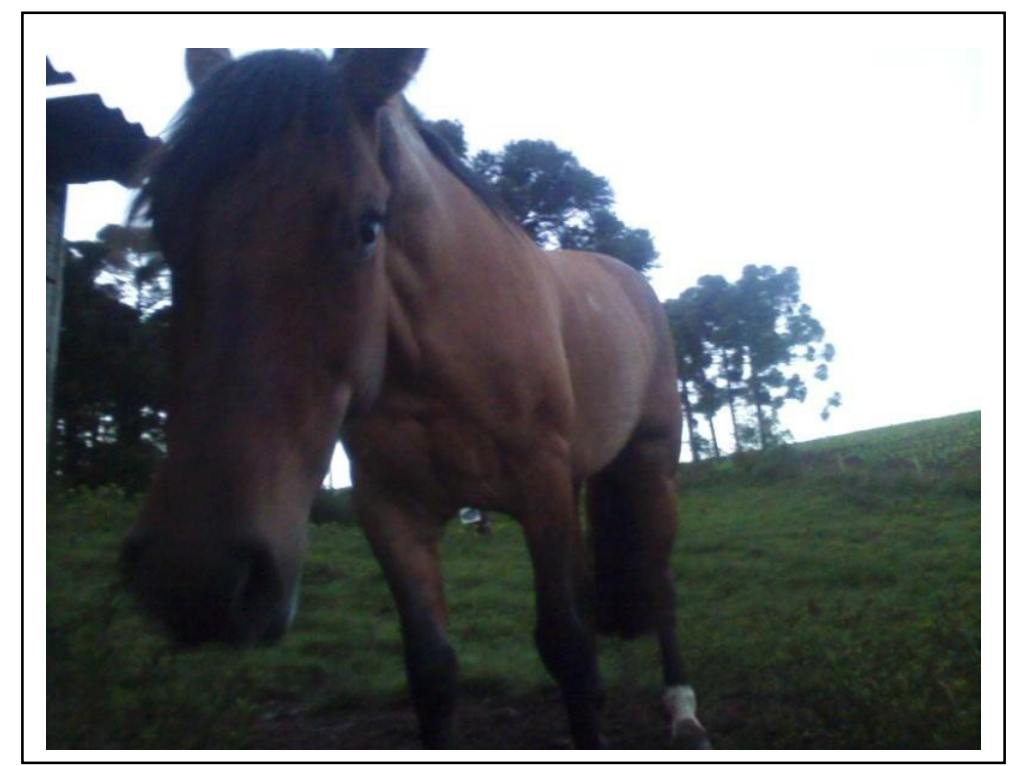

Fonte: Participante da pesquisa - Jovem 01 E.C./K.16 anos/Masc.

\section{Fotografia 04 - Lavoura de hortaliças}

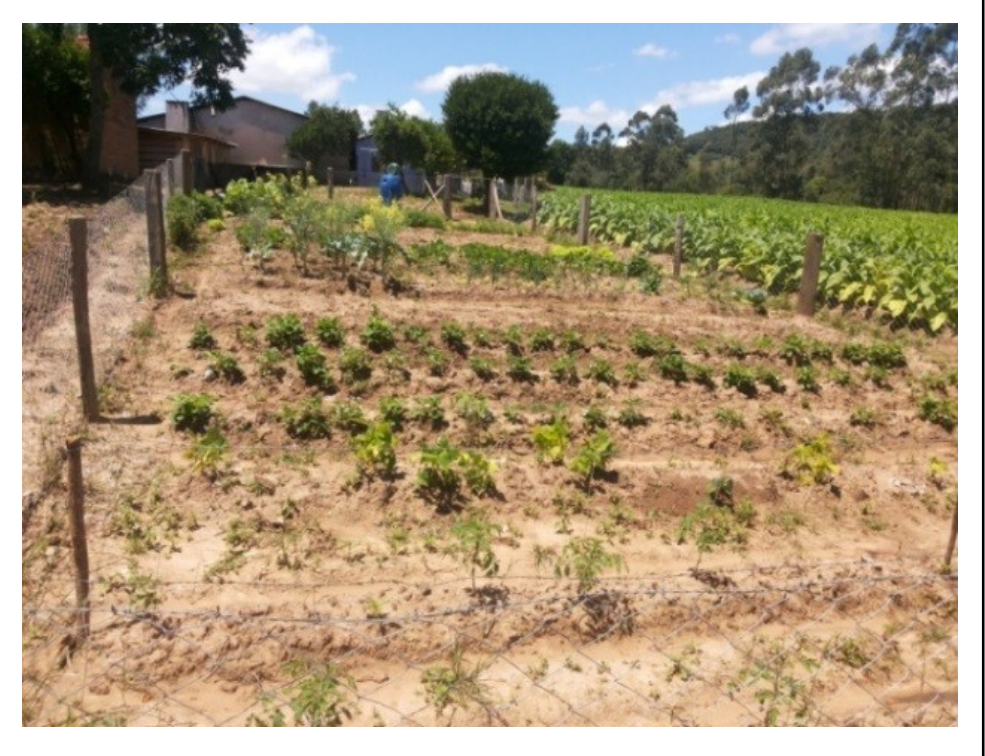

Fonte: Jovem 06 E.C./V./16anos/Masc. 


\section{Fotografia 05 - Lavoura de tabaco}

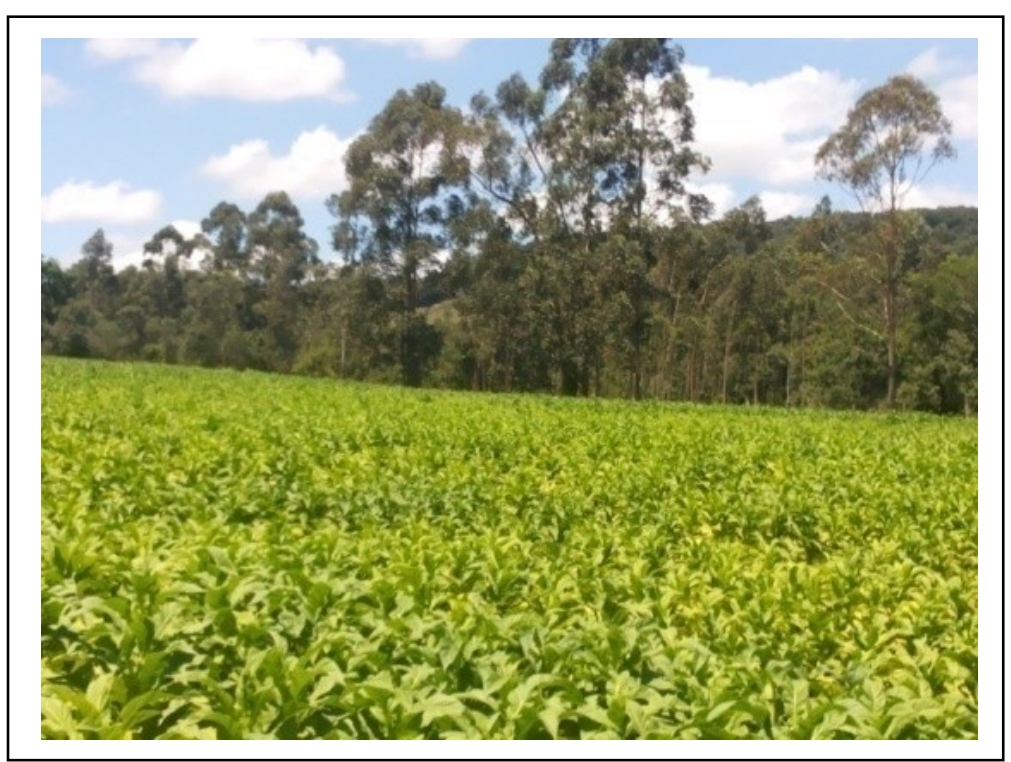

Fonte: Jovem 05/ E.C./S./16 anos/Fem.

\section{Fotografia 06 - Escola}

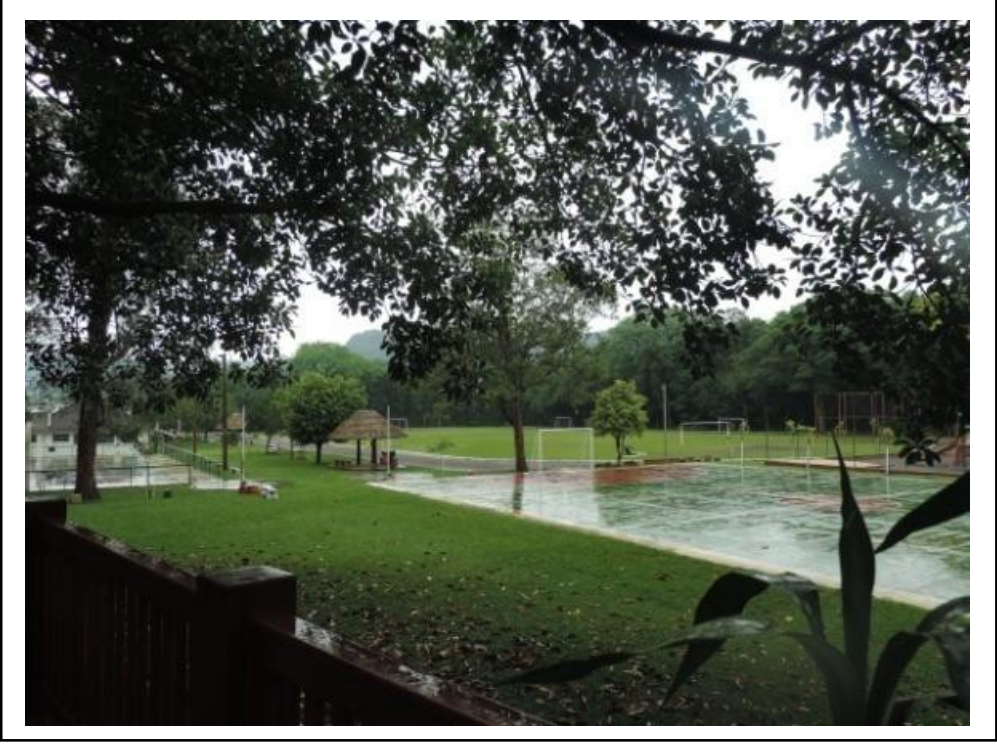

Fonte: Participante da pesquisa - Jovem 10 E.P./ N./15 anos/Mas.

Com relação à representação, visão e expectativas dos jovens quanto à região/território, de forma geral, os jovens da escola comunitária associam a representação da região à cultura do tabaco, afirmando que gostariam que a região fosse mais diversificada econômica e culturalmente, e fosse livre de agrotóxicos. Os jovens da escola privada divergem quanto às ideias que têm sobre o território ou que predominam sobre o Vale do Rio Pardo. Embora alguns também associem a região ao tabaco, à criação de gado, também 
apontam os monumentos históricos, as festas, os pontos turísticos, a cultura germânica e a diversidade cultural como marcas da região.

\section{Considerações finais}

Os resultados da pesquisa apontam para o que a literatura vem sugerindo, que os jovens contemporâneos não constituem um grupo homogêneo, mas, sim, estão elaborando simbolicamente, de forma distinta, sua relação com o mundo, a partir das suas formações sociais e culturais. A fotografia permitiu a análise do olhar fotográfico dos jovens entrevistados, possibilitando conhecer as percepções e significações sociais por meio de recorte dados por eles.

Buscando as aproximações entre as percepções dos jovens participantes, fica claro que a produção do tabaco predominou como representação da região, e, ao mesmo tempo, foi criticada, pois a imagem que muitos idealizam é a da diversidade cultural e econômica. Mesmo que alguns jovens tenham destacado imagens de seu cotidiano, como a paisagem rural, os animais e as hortaliças, todos eles percebem que a produção do tabaco está fortemente associada à região. Da mesma forma, a identidade germânica, indicada como a que marca a região, porém com o reconhecimento da diversidade na sua formação. Os jovens reproduzem certas representações hegemônicas do território, mas boa parte do grupo reconhece que tais representações não são a únicas.

Imagens e narrativas dos jovens, no caso do grupo da escola privada e urbana, evidenciam um destaque aos espaços públicos urbanos de Santa Cruz do Sul, registrando monumentos, praças e parques como representantes para eles da região, assim como um destaque para a escola. De certa forma, o movimento reforça e é fruto da centralidade de Santa Cruz do Sul na região, e muitos espaços fotografados corroboram a identificação do território com a produção do tabaco e com a imigração germânica, pois a enaltecem por meio de seus monumentos. No entanto, a escolha dos jovens pode denotar que espaços

públicos são locais de vivência do grupo, da sociabilidade "presencial" a seu alcance e, portanto, simbolizam o seu território.

Em tempos de fragmentação identitária e desterritorialização, a pesquisa sugere que a juventude que compõe o grupo estudado mantém vínculo forte com seu território, 
tanto de vivência concreta como simbólica. Apesar da ampla possibilidade de conectividade e acesso às TICs, portais para o mundo, os jovens guardam estreita relação com a região, marcada pela sua identificação com a família, escola, cidade e casa/propriedade rural, demonstrando sentimentos de pertencimento e preocupações com o futuro da região.

\section{Referências}

ABRAMO, Helena Wendel. Cenas juvenis. São Paulo: Scritta, 1994.

CANEVACCI, Massimo. Culturas extremas: mutações juvenis nos corpos das metrópoles. Rio de Janeiro: DP\&A, 2005.

CASTELLS, Manuel. A sociedade em rede: economia, cultura e sociedade. São Paulo: Paz e Terra, 1999.

CENSO Demográfico 2010: Banco de dados do IBGE - Instituto Brasileiro de Geografia e Estatística. Disponível em:

<http://www.ibge.gov.br/home/estatistica/populacao/censo2010/>. Acesso em: 5 fev. 2016.

COPQUE, Bárbara Andréa Silva. Meninos fotógrafos ou a fotografia como fonte de conhecimento etnográfico. 2003. 121f. Dissertação (Programa de Pós-graduação em Ciências Sociais) - Universidade do Estado do Rio de Janeiro. Rio de Janeiro, 2003.

ESTEVES, L. C. G; ABROMOVAY, M. Juventude, Juventudes: pelos outros e por elas mesmas. In: ABRAMOVAY, Miriam; ANDRADE, Eliane Ribeiro; ESTEVES, Luiz Carlos Gil

(Org.). Juventudes: outros olhares sobre a diversidade. Brasília: UNESCO, 2009.

FUNDAÇÃO DE ECONOMIA E ESTATÍ́STICA - FEE, 2010. Disponível em:

<http://www.fee.rs.gov.br>. Acesso em: 14 fev. 2016.

2015. Disponível em: http://www.fee.rs.gov.br>. Acesso em: 23 maio 2017.

GUMES, N. V.C. Rg: Jovem- culturas juvenis e a formação das identidades da juventude. Trabalho apresentado no Núcleo de Comunicação e Cultura das Minorias, XXVI Congresso Anual em Ciência da Comunicação, Belo Horizonte/MG, 02 a 06 de setembro de 2003.

HAESBAERT, Rogério. Região, Diversidade Territorial e Globalização. Niterói: DEGEO/UFF, 1999.

HALL, Stuart. A Identidade Cultural na Pós-Modernidade. 11. ed. Rio de Janeiro: DP\&A, 2001. 
KARNOPP, Erica. Desafios e perspectiva para o desenvolvimento de uma agricultura familiar sustentável: O caso da Região do Vale do Rio Pardo, Brasil. Santa Cruz do Sul: EDUNISC, 2003.

LARA, Marcos Rodriguês. Jovens urbanos e o consumo das grifes. In: BORELLI, S. H. S.; FILHO, J. F. (Orgs.). Culturas juvenis no século XXI. São Paulo: Educ, 2008.

MARTÍN-BARBERO, Jesús. A Mudança na percepção da juventude: sociabilidades, tecnicidades e subjetividades entre os jovens. In: BORELLI, S. H. S.; FILHO, J. F. (Orgs.). Culturas juvenis no século XXI. São Paulo: Educ, 2008.

PERALVA, Angelina. O jovem como modelo cultural. Revista Brasileira de Educação. Maio/Jun./Jul./Ago. 1997, n. 5 set./out./nov./dez. 1997.

PERICO, Rafael E. Identidade e território no Brasil. 2009.

RAFFESTIN, Claude. Por uma geografia do poder. São Paulo: Ática, 1993.

SANTOS, Milton. Território e sociedade. 2. ed. São Paulo: Fundação Perseu Abramo, 2001. A natureza do espaço. Técnica e Tempo, Razão e Emoção. São Paulo: EDUSP. 2002.

SILVEIRA, R. L. L da; CAMPOS, H. A. Processos Participativos em Experiências Recentes de Planejamento Regional: O Caso do Vale do Rio Pardo (RS). In REDES - Revista do Desenvolvimento Regional, Santa Cruz do Sul, v. 17, n. 1, p. 203-216, jan./abr. 2012.

SOUZA, C. Z. V. G. Juventude e contemporaneidade: possibilidades e limites. Última década n. 20, CIDPA VIÑA DEL MAR, jun. 2004.

VOGT, Olgário Paulo. A colonização alemã no Rio Grande do Sul e o capital social. Tese (Programa de Doutorado) - Universidade de Santa Cruz do Sul, 2006. 